\title{
Relationship between humor and proposed punishment for crimes: Beware of humorous people
}

\author{
Ruch, Willibald ; Busse, Peter ; Hehl, Franz-Josef
}

\begin{abstract}
It was hypothesized that appreciation of the structural basis and of sexual content in humor is related to punitiveness in different ways. Sixty-eight male subjects served as lay judges and stipulated what would be the just minimum and maximum punishment of committing one of 25 criminal acts and filled in scales relating to humor appreciation, conservatism, dogmatism, and intolerance of ambiguity. Funniness of incongruity-resolution correlated positively with minimum and maximum punishment. Aversiveness of nonsense humor correlated positively with minimum punishment only. Appreciation of sexual content in humor correlates negatively with the extent of demanded punishment for rape but not for other sex-related crimes. Personality scales were predictive of the extent of punishment but to a lesser extent than humor appreciation.
\end{abstract}

DOI: https://doi.org/10.1016/0191-8869(95)00145-V

Posted at the Zurich Open Repository and Archive, University of Zurich

ZORA URL: https://doi.org/10.5167/uzh-77523

Journal Article

Accepted Version

Originally published at:

Ruch, Willibald; Busse, Peter; Hehl, Franz-Josef (1996). Relationship between humor and proposed punishment for crimes: Beware of humorous people. Personality and Individual Differences, 20(1):1-11. DOI: https://doi.org/10.1016/0191-8869(95)00145-V 
This manuscript was published as:

Ruch, W., Busse, P. \& Hehl, F.-J. (1996). Relationship between humor and proposed punishment for crimes: Beware of humorous people. Personality and Individual Differences, 20, 1-12. 


\title{
RELATIONSHIP BETWEEN HUMOR AND PROPOSED PUNISHMENT FOR CRIMES: BEWARE OF HUMOROUS PEOPLE
}

\author{
WILLIBALD RUCH, PETER BUSSE, AND FRANZ-JOSEF HEHL \\ Department of Physiological Psychology, Heinrich-Heine-University of Düsseldorf, \\ Universitätsstraße 1, 40225 Düsseldorf, Germany.
}

\begin{abstract}
Summary-It was hypothesized that appreciation of the structural basis and of sexual content in humor is related punitiveness in different ways. 68 male subjects served as lay judges and stipulated what would be the just minimum and maximum punishment for committing one of 25 criminal acts and filled in scales relating to humor appreciation, conservatism, dogmatism, and intolerance of ambiguity. Funniness of incongruity-resolution correlated positively with minimum and maximum punishment. Aversiveness of nonsense humor correlated positively with minimum punishment only. Appreciation of sexual content in humor correlates negatively with the extent of demanded punishment for rape but not for other sex-related crimes. Personality scales were predictive of the extent of punishment but to a lesser extent than humor appreciation.
\end{abstract}

\section{HUMOR, CONSERVATISM, AND PUNITIVENESS: WHAT IS THE "JUST" PUNISHMENT FOR RAPE AND ARSON?}

Studies aimed at investigating the relationship between punitiveness and humor appreciation face the problem that two lines of thinking exist which lead to opposite predictions. Starting from the first position, one would arrive at the hypothesis that humorous individuals would be less punitive than non-humorous are. Application of the other position, however, allows to predict that punitive individuals will show marked enjoyment of certain forms of humor. The present article will outline these two positions and then provide an empirical examination of the nature of the relationship between humor appreciation and punitiveness.

\section{Humor and tolerance}

One line of thinking associates the "sense of humor"-construct with attributes like tolerant, open-minded, or self-insightful (O'Connell, 1960). This view is, for example, represented by Allport (1954), who claims that "...we have grounds for supposing a person's sense of humor is closely related to his degree of self-insight ... But we venture to assert that humor is probably an important variable in relation to prejudice. Yet if the syndrome of the prejudiced personality is correctly defined ... we can easily believe that humor is a missing ingredient; also that it is a present ingredient in the syndrome of tolerance." (Allport, 1954, p. 437).

However, an empirical test of these proposed relationships has not been undertaken yet. There exists no diagnostic tool allowing to assess sense of humor as understood by Allport. Indirect supporting evidence, however, comes from a study by Dixon, Willingham, Chandler and McDougal (1986) who found a highly significant negative relationship between selfestimated sense of humor (on a 10-point rating scale) and the Rokeach (1960) Dogmatism scale. According to this study, it is the "open," rather than the "closed" mind, who is characterized by a greater sense of humor. According to Rokeach's (1960) theory concerning 
the "open" and "closed" mind, the dogmatic person would be one whose beliefs indicate that he or she has a closed system of thought, is intolerant, sees the world as a threat, has greater belief in absolute authority, and practices a narrow, future-oriented manner of viewing time perspective. Such a belief system would also be resistant to change.

The results of Smith and Levenson (1976), however, contradict the assumption that openminded individuals can laugh at themselves. Smith and Levenson (1976) hypothesized that jokes directed at the membership group their Ss belonged to will be appreciated more by open-minded than by closed-minded individuals. The same (negative) relationship between dogmatism and humor appreciation was expected for control jokes, i.e., identical disparagement jokes that were rewritten to refer to the target as "a guy" rather than the reference group. Finally, only for Ss rejecting their membership group as a reference group, the closed-minded Ss were expected to rate the jokes funnier than the open-minded Ss. The results showed, however, that closed-minded Ss rated all humor significantly funnier than the open-minded Ss. Thus, closed-minded persons appreciate targeted humor more than the open-minded, independent of who the target is. Similarly, studies by Ruch and Hehl (1983, $1985,1986)$ show that the relationship between dogmatism and appreciation of several humor categories tends to be positively rather than negatively. However, the size of the coefficients obtained are small and seldomly significant suggesting that dogmatism is not a powerful predictor of appreciation of non-disparagement humor.

\section{Humor appreciation, conservatism, and "law and order"-attitudes}

The other line of thinking allows to expect a positive relationship between punitiveness and appreciation of particular humor categories. In detail, it is expected that punitive individuals will appreciate jokes and cartoons that are based on the so-called incongruity-resolution structure and they will find humor based on the nonsense structure aversive. This rationale is based on the a two-mode taxonomy of humor and the studies relating to humor appreciation and personality (Ruch, 1992).

A two-mode model of humor appreciation. In the present study a taxonomy of humor is employed which is based on factor analytic studies of both, humor stimuli and responses to humor (see Ruch, 1992). As regards the stimulus side, analyses of different sets of jokes and cartoon yielded three dimensions, two of which being characterized by common structure (but are heterogeneous with respect to content). Whereas incongruity is a necessary ingredient of any form of humor, the two structural factors mainly differ with respect to the degree of resolution obtainable for the incongruity. Incongruity-resolution (INC-RES) jokes and cartoons are characterized by punch lines in which the surprising incongruity can be completely resolved. The common element in this type of humor is, that the recipient first discovers an incongruity which is then fully resolvable upon consideration of information available elsewhere in the joke or cartoon. Although individuals might differ with respect to how they perceive and/or resolve the incongruity, they have the sense of having "gotten the point" or understood the joke once resolution information has been identified.

Nonsense (NON) humor, the other structural factor consistently emerging, also has a surprising or incongruous punch line, however, "... the punch line may 1) provide no resolution at all, 2) provide a partial resolution (leaving an essential part of the incongruity unresolved), or 3) actually create new absurdities or incongruities." (McGhee, Ruch \& Hehl, 1990 , p. 124) In nonsense humor the resolution information gives the appearance of making sense out of incongruities without actually doing so.

Sexual (SEX) humor, the third category, may be based on one structure or the other, but is homogeneous with respect to the sexual content involved. Sex jokes and cartoons typically have two loadings: one on the sexual humor factor and a second one on one of the two 
structure factors. According to their loading patterns, the items of the general sexual humor category roughly can be subdivided into three classes of "pure" sexual humor (in which the content largely overpowers the structure), incongruity-resolution based sexual humor and nonsense based sexual humor.

As regards the dimensions of responses to humor, the factor analytic studies suggest the appreciation of humor is defined by two nearly orthogonal components of positive and negative responses which are best represented by ratings of "funniness" and "aversiveness." Maximal appreciation of jokes and cartoons consists of high funniness and low aversiveness, while minimal appreciation occurs if the joke is not considered funny but is found aversive. However, a joke can also be considered not funny but be far from being aversive; or it can make one laugh although there are certain annoying aspects (e.g., one can consider the punch line original or clever but dislike the content of the joke).

The 3 WD Humor Test ("3 Witz-Dimensionen"; Ruch, 1983) was constructed to assess funniness and aversiveness of these three humor dimensions. There are three versions of this humor test. Translation of the 3 WD into French, Hebrew, Italian, Turkish, and English allowed to study the cross-national stability of this taxonomy (see for example, Ruch, Accoce, Ott \& Bariaud, 1991).

Personality and appreciation of humor. The rationale for deriving hypotheses about the link between appreciation of the three types of humor and various domains of personality is outlined elsewhere in more detail (Ruch, 1992). In short, as regards the structural factors, the model suggests that the two structures mainly differ with respect to the degree of resolution obtained. In incongruity-resolution humor a complete resolution of the incongruity is possible while there are residual traces of incongruity in nonsense humor. Thus, in the first category the resolution of incongruity contributes to appreciation whereas in factor two appreciation is based on the existence of residual incongruity. This consideration and evidence from other sources led to the hypotheses that appreciation of the incongruityresolution structure is a manifestation of a broader need of individuals for contact with structured, stable, unambiguous forms of stimulation, whereas appreciation of the nonsense structure in humor reflects a generalized need for uncertain, unpredictable, and ambiguous stimuli. Personality variables, like intolerance of ambiguity and conservatism incorporate the aspect of avoidance of high stimulus uncertainty (in information theory sense, e.g., complexity, novelty, ambiguity, incongruity, unfamiliarity, unpredictability) and were therefore hypothesized to be predictors of funniness of INC-RES based humor and aversiveness of nonsense-based humor. In fact, these hypotheses could be verified for diverse samples or subgroups, for different conservatism scales, and in a cross-cultural context (Forabosco \& Ruch, 1994; Ruch, 1992).

Studies of appreciation of sexual humor and sexual behavior and attitudes to sex suggested that a direct or positive relationship exists rather that the inverse one as suggested by Freudian thinking. This was particularly so when only the sexual content of the sexual humor category was considered (i.e., after eliminating appreciation the structural basis) when testing the hypothesis (Forabosco \& Ruch, 1994). Among the predictors of appreciation of content in sexual humor are scales of sexual libido, sexual satisfaction, sexual permissiveness, sexual pleasure and experience, but also toughmindedness, extraversion, and male sex (Ruch, 1992). In short, individuals differ in their degree of positive attitude toward sexual matters, and this tendency is extended to appreciation of sexual content in humor. However, the combination of sexual content and the two structures yields quite different predictors (see Ruch, 1992). 
The present study

The present study examines the relationship between punitiveness and humor appreciation following the second strain of thinking just outlined. Thus, it is assumed that humor goes along with punitiveness positively rather than negatively. Punitiveness is operationalized by what lay judges consider to be the "just" punishment for different crimes. Like in court practice, a differentiation of minimum and maximum punishment will be undertaken since also the law considers a range of punishment depending on the severeness of the criminal act. Furthermore, one can expect that these two judgments are sensitive for different aspects of the punitive attitudes. The minimum punishment score emphasizes the aspect of whether offenses should be punished at all or only mildly. Individuals with a law and order-attitude may insist that all crimes should be punished. For them, it would not be just that an offender can come away with it; so they will suggest higher minimum punishments. The maximum punishment scores relate to the intensity of punishment and might involve considerations of revenge and prevention of further crimes.

Three sets of hypotheses will be tested in the present study. One covers the relationship between general punitiveness and appreciation of humor structure. The second one refers to the relationship between punitiveness with regard to crimes against the sexual selfdetermination and appreciation of sexual content in humor. The third one refers to the relationship between selected personality traits and punitiveness.

Punitiveness and appreciation of humor structure. Given the theoretical framework outlined above, it can be hypothesized that there are positive correlations between extent of punishment and funniness of incongruity-resolution humor (Hypothesis 1) and aversiveness of nonsense humor (Hypothesis 2). Thus, it is assumed that similar mechanisms underlie the attitude that severe punishment is just for violating laws and the need for resolution in humor. Being afraid of disorganization is considered to be the psychological antecedent of the punitiveness component of conservatism (Wilson, 1973); the insisting on strict rules is a pattern developed to prevent being exposed to that threat. Similarly, the fact that incongruityresolution humor allows for a complete resolution of the incongruity induced by the punch line should appeal to those who generally have a high need for such closure. They, for a similar reason, will find nonsense humor more aversive. Punch lines of this sort of humor do not allow a complete closure; there always is a residue of incongruity. The remaining incongruity frustrates the need for closure, and thus, some subjects will respond to this type of humor negatively, i.e., with enhanced aversiveness scores.

Punitiveness and appreciation of sexual content. The question arises whether humor content relates to punishment as well. There are several crimes against the sexual selfdetermination or otherwise relating to sexual behavior, such as sexual abuse of a child, incest, or rape. In general, individuals appreciating sexual content in humor are sexually permissive, hedonistic, of high sexual libido, and tough-minded (Ruch \& Hehl, 1986, 1988). Thus, it might be, that these individuals will be more tolerant or less punitive with respect to sexual crimes than individuals with little enjoyment of sexual humor content. Thus, Hypothesis 3 states that appreciation (funniness and aversiveness) of sexual content will be negatively correlated with the extent of punishment of crimes related to sexual selfdetermination. Since the hypothesis relates to the sexual content only, the variance relating to the structure (most of the sexual jokes and cartoons in the $3 \mathrm{WD}-\mathrm{K}$ are based on the incongruity-resolution structure) will be removed prior to testing. It should be noted, however, that due to that presence of structure variance, the category of sexual humor will be positively correlated with general punitiveness (albeit to a lower extent that INC-RESf).

Personality and punitiveness. Finally, positive correlations between punitiveness and conservatism, intolerance of ambiguity, and dogmatism are to be expected. The judgment of 
what the "just" punishment for those breaching the law is related to the law and orderattitudes of the conservatives and the associated fear of disorganization. Likewise, intolerance of ambiguity can be considered to be a motivating force for not leaving breaking the law unpunished. Finally, the association with the closed mind might be based on the dogmatic person's intolerance, the view of the world as threatening, the greater belief in absolute authority, and consequently, the wish that state authority should punish those who don't act by the rules and contribute to make the world more threatening.

\section{METHOD}

\section{$\underline{\text { Subjects and procedure }}$}

There were 68 male university students of different subjects (with the exception of psychology) who were paid for their participation. Their age ranged from 20 to 31 years, with a mean of 24.4 and a standard deviation of 3.0 years. Ss were tested individually; the testing session lasted approximately 90 minutes.

\section{$\underline{\text { Material }}$}

Extent of punishment. Ss were presented with a list of 25 criminal acts originating from the German Federal Handbook of Laws relating to criminal offenses ${ }^{1}$. Furthermore, they were provided with short juridical definitions of these criminal acts extracted from the book of law. Ss were required to stipulate what the considered to be "just" minimum and maximum sentences for breach of the law. The range was from warning (0) to death sentence (8). In order to assure an equal understanding of the scale each of the steps in between was assigned an amount of punishment $(1=$ maximum 3 month, $2=$ maximum 1 year, $3=$ maximum 3 years, $4=$ maximum 6 years, $5=$ maximum 10 years, $6=$ maximum 15 years, 7 = life time imprisonment). Total scores for minimum and maximum sentences were derived by adding all 25 acts. Finally, a total punishment score was derived by summing up minimum and maximum punishment.

Humor Appreciation. Form K of the 3-WD humor test (Ruch, 1983) contains 50 jokes and cartoons, which are rated on "funniness" and "aversiveness" using two 7-point scales ranging from not at all funny (or aversive) to very funny (or aversive). The jokes and cartoons are presented in a test booklet with two or three items on a page. The instructions are typed on the separate answer sheet which also contains the two sets of rating scales. The first five items are used for "warming up" and are not scored.

Six scores can be derived from the test: three for funniness of incongruity-resolution, nonsense and sexual humor (i.e., INC-RESf, $\mathrm{NON}_{f}$, and $\mathrm{SEXf}_{\mathrm{f}}$ ) and three for their aversiveness (i.e., INC-RES $\mathrm{a}, \mathrm{NON}_{\mathrm{a}}$, and $\mathrm{SEX}_{\mathrm{a}}$ ). Additionally, two structure preference

\footnotetext{
${ }^{1}$ Footnote

${ }^{1}$ The German terms for these crimes were Beischlaf zwischen Verwandten, Bestechung, Betrug, Bildung bewaffneter Horden, Diebstahl, Doppelehe (Bigamie), Freiheitsberaubung, Gefangenenbefreiung, Geldfälschung, Hausfriedensbruch, Körperverletzung, Körperverletzung mit Todesfolge, Landesverrat,

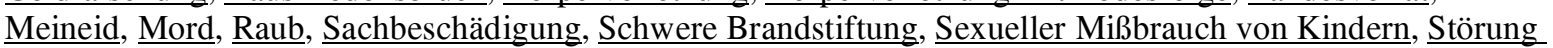
der Religionsausübung, Unterlassene Hilfeleistung, Urkundenfälschung, Vergewaltigung, Verleumdung, and Wahlfälschuung.
} 
indices (SPIs) were derived by subtracting NONf from INC-RESf (SPIf) and INC-RESa from $\mathrm{NON}_{\mathrm{a}}\left(\mathrm{SPI}_{\mathrm{a}}\right)$. High scores always indicate preference of incongruity-resolution humor over nonsense humor.

Conservatism. The German version (Schneider \& Minkmar, 1972) of the Wilson and Patterson C-Scale is 40 item-questionnaire in a 'catchphrase' format utilizing a trichotomous answer format. The items usually form a potent general factor of conservatism vs. liberalism.

Intolerance of Ambiguity. The IA-Scale by Kischkel (1984) is a 14-item scale in a 5-point answer format measuring the extent to which individuals consider ambiguity as a source of threat rather than challenge.

Dogmatism. The dogmatism-scale by Brengelmann and Brengelmann (1960) is a 14-item scale in a yes/no-answer format measuring individual differences in open- vs. closedmindedness.

\section{RESULTS}

Means and standard deviations of minimum and maximum punishment were computed for each of the 25 crimes and are presented in Figure 1. The offenses were rank-ordered for maximum punishment.

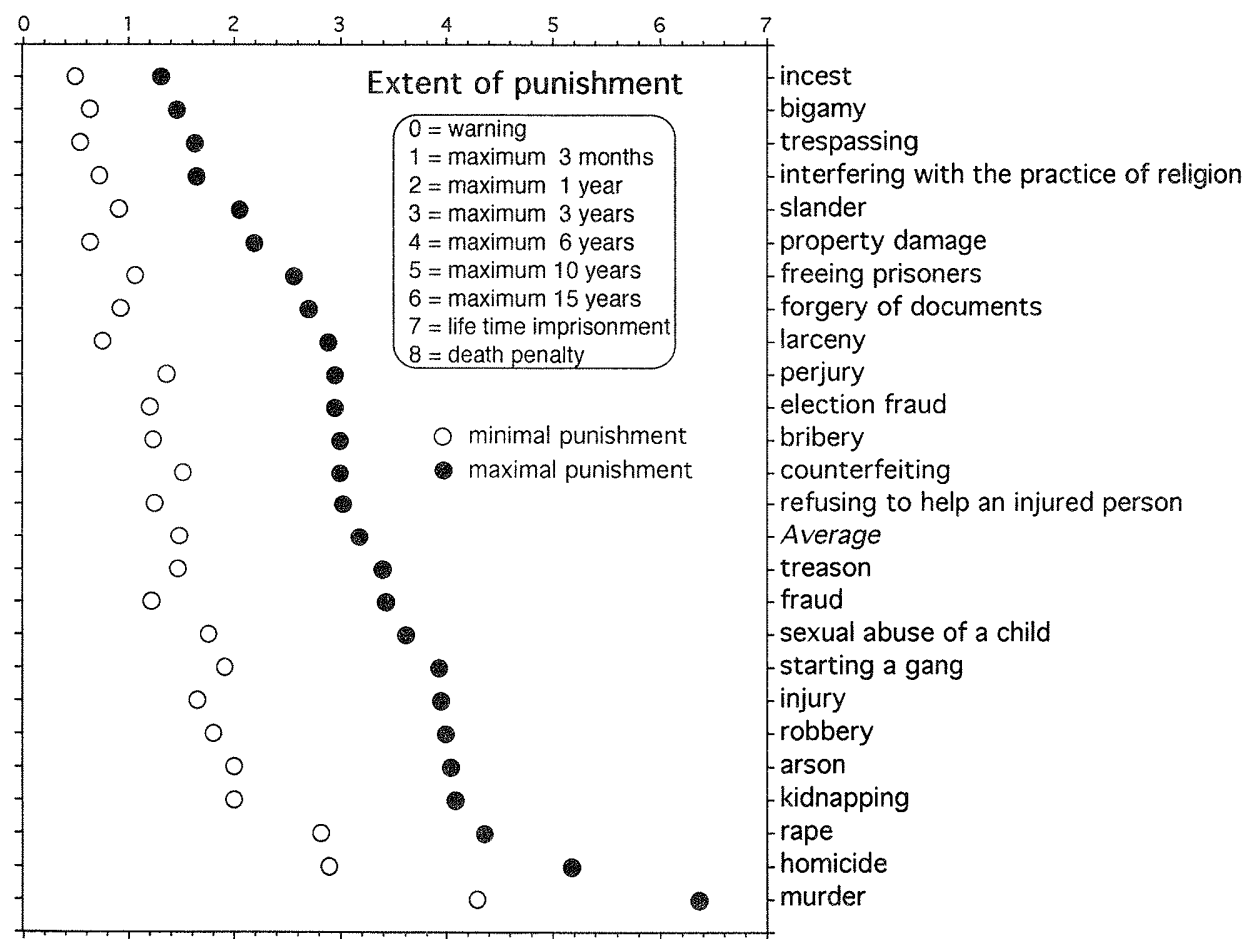

Figure 1. Rated minimal and maximal extent of punishment for different criminal acts.

Figure 1 shows that subject discriminated well among the different crimes as regards perceived severeness. Among minimum punishment, the lowest means were obtained for incest (0.50), trespassing (0.54), and bigamy (0.63) and the highest for rape (2.82), homicide (2.90), and murder (4.29). For maximum punishment, incest (1.31), trespassing (1.63), and bigamy $(1.47)$ were treated mildest, while rape $(4,37)$, homicide $(5.18)$, and murder $(6.37)$ were considered most severely. The rank order of the 25 crimes is highly similar for mean minimum and maximum punishment $(\underline{\mathrm{R}}(25)=0.97, \underline{\mathrm{P}}<0.001)$. Also, minimum and 
maximum punishment are correlated with each other across all 68 Ss. The correlation coefficients for the single items ranged from 0.33 (property damage) to 0.82 (rape), and the total scores yielded a coefficient of $0.68(\underline{\mathrm{P}}<0.001)$.

In general, the extent of punishment is comparably low; the average of the suggested punishments were 1.48 and 3.19 for minimum and maximum punishment, respectively. Also, the punishment suggested to be just by the present subjects was most often within the range given by the book of law, and mostly closer to the minimum than to maximum punishment. However, for refusing to help an injured person the suggested punishment (Mode $=3$ years) exceeded the boundaries considered by the law (maximum of one year). Also, death penalty (not a category in German law) was suggested (by altogether seven students) twice as being the lower bound for murder, and 16 times as the maximum punishment (mainly for murder and homicide, but also for 5 other crimes).

Humor and punitiveness. Product moment correlations between the humor scales and minimal, maximal, and total punishment were computed. The results are reported in Table 1.

Table 1. Correlations between punishment scales and humor appreciation

3 WD humor appreciation

\begin{tabular}{lcccccc} 
& INC-RES & $\mathrm{NON}_{\mathrm{f}}$ & $\mathrm{SEX}_{\mathrm{f}}$ & ${\mathrm{INC}-R E S_{\mathrm{a}}}$ & $\mathrm{NON}_{\mathrm{a}}$ & SEX $_{\mathrm{a}}$ \\
\hline Minimum punishment & $.42^{* * *}$ & .03 & $.31 * *$ & .00 & $.22 \dagger$ & .10 \\
Maximum punishment & $.32 * *$ & -.02 & .14 & .03 & .13 & .17 \\
Total punishment & $.40^{* * *}$ & .00 & $.24 \dagger$ & .02 & .19 & .15 \\
& & & & & & \\
\hline
\end{tabular}

Note. $\dagger \mathrm{p}<.05$ (one-tailed); ** $\mathrm{p}<.01$ (two-tailed); *** $\mathrm{p}<.001$.

Table 1 gives support for the hypothesis that extent of punishment is correlated with humor appreciation. Funniness of incongruity-resolution humor correlates positively with minimal, maximal, and total punishment. Hence, Hypothesis 1 can be regarded as confirmed. Furthermore, minimum and total punishment (but not maximum punishment) also correlate positively with funniness of sexual humor. These coefficients are numerically lower than the ones for INC-RESf.

The positive correlation between punishment and aversiveness of nonsense fails to be significant except for minimum punishment. This might be due to the fact that mean aversiveness is rather low $(\underline{M}=10.37)$, and also the variance of $\mathrm{NON}_{\mathrm{a}}(\underline{\mathrm{SD}}=11.85)$ in the present sample is only half to two thirds of the variance of other samples studied (Ruch, 1992) resulting in a skewed distribution. Hence, Spearman rank-order correlations were computed and yielded the expected significant positive coefficients for minimal, maximal, and total punishment $(\underline{\mathrm{Rs}}=.28, .28$, and .31 , respectively, all $\underline{\mathrm{Ps}}<.05)$. Thus, Hypothesis 2 yielded support as well.

As expected, funniness of nonsense humor is not correlated with the punishment scales. Also, aversiveness of incongruity-resolution humor and of sexual humor do not correlate with the punishment scales.

Analysis of single criminal acts. Product-moment correlations between the humor scales and the minimum and maximum punishment ratings of the single 25 crimes were computed. The results for the three funniness scales are reported in Table 2. 
Table 2. Correlations between humor appreciation and punitiveness

\begin{tabular}{|c|c|c|c|c|c|c|}
\hline \multirow[b]{2}{*}{ Criminal acts } & \multicolumn{2}{|c|}{ INC-RES $_{\mathrm{f}}$} & \multicolumn{2}{|c|}{$\mathrm{NON}_{\mathrm{f}}$} & \multicolumn{2}{|c|}{$\mathrm{SEX}_{\mathrm{f}}$} \\
\hline & $\min$ & $\max$ & $\min$ & $\max$ & $\min$ & $\max$ \\
\hline incest & $.27 *$ & $.33 * *$ & -.01 & -.05 & $.25^{*}$ & $.27 *$ \\
\hline bigamy & $.33 * *$ & $.36^{* *}$ & .15 & .02 & $.28 *$ & .23 \\
\hline trespassing & .15 & .13 & -.05 & .02 & .17 & .09 \\
\hline interfering with the practice of religion & .19 & .21 & .04 & .01 & .09 & .05 \\
\hline slander & $.25 *$ & $.37 * *$ & .07 & .23 & .08 & .18 \\
\hline property damage & .13 & $.24^{*}$ & -.02 & -.08 & .16 & .09 \\
\hline freeing prisoners & .10 & .05 & .00 & .01 & -.05 & -.11 \\
\hline forgery of documents & $.31 *$ & $.25^{*}$ & .11 & -.03 & $.30 *$ & .12 \\
\hline larceny & .08 & $.26^{*}$ & -.12 & .01 & .11 & .20 \\
\hline election fraud & $.27^{*}$ & .14 & .12 & .04 & $.26^{*}$ & .08 \\
\hline perjury & $.37 * *$ & .21 & .00 & -.06 & $.29 *$ & .10 \\
\hline counterfeiting & $.35 * *$ & .16 & .07 & -.09 & $.33 * *$ & .10 \\
\hline bribery & .16 & .14 & .09 & .14 & .08 & .01 \\
\hline refusing to help an injured person & .14 & $.26^{*}$ & -.02 & -.14 & .17 & .18 \\
\hline treason & $.25^{*}$ & .18 & .05 & -.07 & $.33 * *$ & .07 \\
\hline fraud & $.30^{*}$ & .20 & .10 & .18 & .19 & .13 \\
\hline sexual abuse of a child & $.32 * *$ & $.24 *$ & -.14 & -.07 & .18 & .08 \\
\hline starting a gang & $.26^{*}$ & .15 & -.08 & -.02 & .14 & -.09 \\
\hline injury & $.30 *$ & .12 & .11 & .01 & .18 & .03 \\
\hline robbery & $.25^{*}$ & .20 & -.03 & -.06 & .20 & .09 \\
\hline arson & $.39 * *$ & .23 & .01 & -.05 & $.28 *$ & .01 \\
\hline kidnapping & $.30^{*}$ & $.25^{*}$ & .09 & .02 & .14 & .04 \\
\hline rape & $.27 *$ & $.24 *$ & -.10 & -.01 & .13 & .01 \\
\hline homicide & $.37 * *$ & .12 & .00 & -.07 & $.30 *$ & .07 \\
\hline murder & $.34 * *$ & .22 & .02 & -.04 & $.30 *$ & .15 \\
\hline
\end{tabular}

Note. $* \mathrm{p}<.05, * * \mathrm{p}<.01$.

Table 2 supports the assumption that the different criminal acts yield a different pattern of correlation with the humor scales. INC-RES $f$ correlates significantly positively with minimum punishment for 18 of the 25 items, with 10 of the coefficients exceeding .30. The highest coefficients were obtained for arson, perjury, homicide, counterfeiting money, murder, bigamy, sexual abuse of a child, forgery, injury, fraud, and kidnapping. The items with no significant coefficients refer to larceny, freeing prisoners, property damage, refusing to help an injured person, trespassing, interfering with the practice of religion, and bribery.

In the analyses of the maximum punishment ratings 10 crimes were significant with slander, incest, and bigamy yielded the highest coefficients. Interestingly, these are crimes with a low average minimum and maximum punishment rate. Again, this goes along with the idea of insisting on strict punishment of even comparably mild breaches of law.

None of the items correlates significantly with $\mathrm{NON}_{\mathrm{f}}$. SEXf correlated significantly positively with maximum punishment of 10 criminal acts, with counterfeiting money, treason, murder, forgery, and homicide obtaining coefficients higher than .30. Only one of the maximum punishment ratings correlated with $\mathrm{SEX}_{\mathrm{f}}$. Subject appreciating sexual humor demand higher punishment for incest than those scoring low in SEXf.

The few significant correlations between punitiveness and aversiveness of humor should be mentioned too. All except four of the 50 correlations between $\mathrm{NON}_{\mathrm{a}}$ and minimum and maximum punishment were positive but only four of them were significant, all of them relating to minimum punishment. In detail, $\mathrm{NON}_{\mathrm{a}}$ correlated positively with minimum 
punishment of trespassing (0.31), homicide (0.26), starting a gang (0.24), and interfering with the practice of religion $(0.24, \underline{\text { Ps }<0.05)}$.

The extent of punishment did not correlate with INC-RESa. Finally, SEXa correlated positively with minimum and maximum punishment for freeing prisoners (0.28) and maximum punishment for rape $(0.24, \underline{\text { Ps }}<0.05)$; the latter is providing support for Hypothesis 3.

Punitiveness and sexual content. Most of the coefficients for minimum and maximum punishment are much lower for $\mathrm{SEX}_{\mathrm{f}}$ than for INC-RESf. For maximum punishment, the greatest difference in size of the coefficients was observed for sexual abuse of a child and rape. An increase was observed for treason only. For minimum punishment, the highest reduction in relation to INC-RESf was observed for kidnapping and assuming that the difference between INC-RES and SEX is mainly the content, then, it is suggested that Ss appreciating sexual content are less punitive with respect to crimes relating to sexual acts. In order to test Hypothesis 3 , partial correlations between minimum punishment and funniness

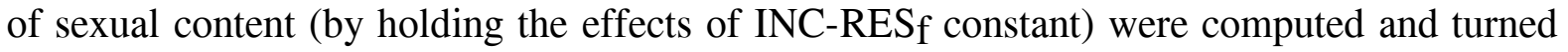
out to be nonsignificant and lower in size for bigamy (0.06), incest $(0.08)$, sexual abuse of a child (-0.09), and rape (-0.11) indicating that the observed zero order correlations were due to the structural properties of sexual humor. Similarly, for maximum punishment the correlations for bigamy (-0.06), incest (0.06), and sexual abuse of a child (-0.15) were much lowered in size after partialling out the effects of INC-RESf. However, only for rape $(\underline{r}=-$ $0.26 ; \underline{\mathrm{P}}<0.05)$ the just maximum punishment is negatively correlated with funniness of sexual content in humor. Thus, individuals enjoying the content in sexual humor plead for lower maximal sentence for those committing rape than individuals with less appreciation (funniness and aversiveness) of the sexual content. These correlations, however, have to be replicated before interpretation is warranted.

Personality correlates of punitiveness. Product moment correlations between the punitiveness scales and conservatism, rigidity, intolerance of ambiguity, and dogmatism were computed and are reported in Table 3.

Table 3. Correlations between personality variables and minimal and maximal punishment

\begin{tabular}{llll}
\hline & Conservatism & $\begin{array}{c}\text { Intolerance of } \\
\text { Ambiguity }\end{array}$ & Dogmatism \\
\hline Minimal punishment & $.32^{* *}$ & $.32^{* *}$ & $.28^{*}$ \\
Maximal punishment & $.31^{*}$ & .14 & .13 \\
Total punishment & $.34 * *$ & $.24 *$ & $.22 \dagger$ \\
& & & \\
\hline
\end{tabular}

$\underline{\text { Note. }} \dagger \underline{\mathrm{p}}<.05$ (one-tailed); $* \underline{\mathrm{p}}<.05$ (two-tailed); $* * \mathrm{p}<.01 ; * * * \mathrm{p}<.001$.

Table 3 shows that the signs of the coefficients are all in the predicted direction, however, not all of them were significant. As expected, conservatism predicts minimal, maximal, and total punishment. The coefficients are roughly equal in size. Dogmatism and intolerance of ambiguity are correlated with minimal and total punishment, but not with maximum punishment. Note, however, that funniness of incongruity-resolution humor seems to be a better predictor of punishment than the conservatism scale (or the other personality scales).

Favouring death penality should not be related to conservatism but also to toughmindedness (Eysenck, 1954). Since the German version of the C-Scale does not consider a separate scoring of tough vs. tendermindedness (or idealism/realism) a principal components analysis was performed yielding two unrotated axes easily identified as 
conservatism and toughmindessness. In order to study the role of these two dimensions in punitiveness in more detail two indices of severeness and mildness of punishment were computed by summing up the number of responses in the categories "death penalty" $(=8)$ and "warning" (=0), respectively. The individuals including death penality in their judgements were indeed higher in the factors of conservatism $(\underline{r}=.35)$ and toughmindessness $(\underline{\mathrm{r}}=.35$; all $\underline{\mathrm{Ps}}<.01)$. Considering a warning as being sufficient in a larger number of crimes correlated with conservatism $(\underline{r}=-.45 ; \underline{\mathrm{P}}<.001)$ but not with toughmindedness $(\underline{\mathrm{r}}=.04 ; \underline{\mathrm{ns}})$. However, while the factor of conservatism correlated with both minimum and maximum punishment ( $\underline{\mathrm{r} s}=.37$ and .36 ; all $\underline{\mathrm{P}} \mathrm{s}<.01$ ), the positive correlation between toughmindedness and maximum punishment $(\underline{r}=.12)$ failed to be significant.

Differences between minimum and maximum punishment? For most of the scales, the coefficients for maximum punishment are lower than the ones for minimum punishment (Tables 1, 2, and 3). This cannot be explained by a smaller variance. On the contrary, there is more variability $(\underline{S D}=23.31)$ in total maximum punishment scores than in the total minimum punishment scores $(\underline{\mathrm{SD}}=19.33)$. Also, for the individual crimes, the variance for maximum punishment was higher than for minimum punishment for all crimes except for four with the highest means, namely rape, sexual abuse of a child, homicide, and murder.

\section{I S C US SION}

The results clearly support the hypothesis that humor appreciation is correlated positively with punitiveness, i.e., individuals appreciating humor of a particular type are more punitive than those who are "humorless" with respect to appreciation of forms of humor. However, as predicted, it is only the incongruity-resolution humor category which is responsible for that relationship. Furthermore, taking into account that most sexual humor is based on the incongruity-resolution structure, the results found for sexual humor are also compatible with this hypothesis. Thus, contrary to every-day belief, it is not the individual lacking humor that is punitive, but the "humorous" one. This does not exclude the possibility that a "sense of humor" (especially when the trait definition emphasizes the philanthropic elements) might go along with higher tolerance and the tendency to forgive rather than taking revenge.

More precisely, the present results show that INC-RES $\mathrm{f}$ is a predictor of harsh minimum punishment of almost all crimes and harsh maximum punishment of several of the less severe crimes. The common denominator for this pattern of results seems to be the aim to make sure that offenders should not come away with, no matter whether the breach of the law was comparably mild or not. There should be atonement for having committed offenses, no matter how severe it was. Thus, INC-RESf seems to be the predictor of the threshold rather than the intensity of punitiveness; any offenders need to expiate, but the high scorers in INCRES $f$ do not necessarily demand highest degrees of punishment.

These results fall in line with prior research showing that Ss scoring high in funniness of incongruity-resolution humor describe themselves in questionnaires as favouring "law and order"-attitudes (Ruch et al., 1991), being intolerant of minorities (Ruch \& Hehl, 1985), and against sexual permissiveness (Ruch \& Hehl, 1988). It is of interest to note that while aggressiveness is not a predictor of this humor category, a scale of inhibition of aggression turned out to be a predictor of funniness of incongruity-resolution humor in two samples (Ruch \& Hehl, 1985). Other predictors, like superego strength (16PF-G) or low Psychoticism (Ruch \& Hehl, 1985) complete the picture and support the view that Ss scoring high in INCRESf have internalized the rules of society, behave according to these rules, and want that those breaking the rules get severely punished. Thus, while incongruity-resolution humor is not related to aggression at the level of direct expression of behavior, it relates to 
punitiveness at the attitudinal level. It is not the individual who acts out aggressive impulses that also finds INC-RES humor funny, but the one that helds punitive attitudes. Humor involves a play with ideas and it apparently relates more strongly to mental representation of actions rather than with exerting the action itself.

It has to be remembered in this context that the results found cannot be explained by content overlap. The type of humor covered by the incongruity-resolution category varies in content; it is not restricted to jokes or cartoons which are overtly aggressive, cynical, or somehow relating to punitiveness or depicting characters breaking the law. Thus, the correlation between punitiveness and funniness of incongruity-resolution humor emerges because both are related to conservatism or the principle underlying conservatism (Wilson, 1973). The common denominator of incongruity-resolution humor is that such humor allows for a complete resolution of the incongruity induced by the punch line and this closure is more enjoyable to conservatives than to liberals. Likewise, individuals differ in the tendency to be afraid of disorganization (which is considered to be the psychological antecedent of the punitiveness component of conservatism; Wilson, 1973), and insisting on strict rules is a pattern conservatives developed to prevent being exposed to that threat.

Humor appreciation as an index of punitive attitudes? While enjoyment of humor can be seen to be embedded into that personality background, it is of interest to note that humor appreciation was a better predictor of punitiveness than conservatism, intolerance of ambiguity, or dogmatism. This might be due to its lack of transparency as regards to what is being measured. The results of the present study and the ones of prior ones (see Ruch, 1992) seem to allow for beginning to discuss the prerequisites for a potential use of the $3 \mathrm{WD}$ humor test as an objective test (in the Cattellian sense) of personality. That is, humor appreciation might be seen as a subtle index for assessing punitiveness in an indirect way. There is a long tradition along these lines; for example, under the guise of assessing one's sense of humor the scores of the IPAT humor test of personality (Cattell \& Tollefson, 1966) were used to draw inferences about an individual's location on personality dimensions, like intelligence, extraversion, or anxiety. Thus, one might think of using the $3 \mathrm{WD}$ as an indirect assessment of punitiveness, law and order-attitudes, or the authoritarian personality. These are all contents which are easily identified in regular questionnaires and thus are easily faked. Results found for other tests of humor appreciation support this claim as well (Cooper, Kline \& May, 1986; Kline \& Cooper, 1984); a measure of "preference for outright rather than subtle humour" correlated with various measures of the authoritarian personality. Inspection of the jokes of the pole of "outright non-subtle humour" showed that this category consisted exclusively of incongruity-resolution based humor.

Enjoyment of sexual content in humor seems to go along with a mildness with respect to the maximum punishment for rape. Individuals with lower (structure-removed) funniness and higher aversiveness scores demand higher punishment for this crime whereas Ss appreciating sexual content tended to give lower punishment scores. This tendency did not apply to crimes like bigamy, incest, or sexual abuse of a child. There are differences among these crimes, however. Only rape is fed by, among other factors, high sexual libido, the element related to appreciation of sexual content in humor (Ruch \& Hehl, 1988). Incest or sexual abuse of a child do not refer to that dimension. Nevertheless, since this result is based on one crime only further investigations of the issue are required. It should be noted, however, that the relationship found was at least for the funniness aspect overlaid by the structural properties of humor and hence future testings of the hypotheses related to humor content should be careful in partialling out of the structural variance.

All in all, the coefficients for minimum punishment were higher than the ones for maximum punishment. This holds for humor appreciation as well as for the personality scales. Minimum punishment relates to whether breaches of the law should be punished or 
not, whether there should be a warning or other comparably mild punishments, or whether there should be already a more or less severe punishment. It turned out that Ss high in conservatism, intolerance of ambiguity, dogmatism, and in funniness of incongruityresolution humor demand that there should be no pardon for those breaching the law. If a crime was committed the offender should get his/hers just punishment without pardon. The factor of conservatism was most highly correlated with the (low) number of warnings; hence, minimum punishment seems to be the more sensitive indicator for the "law and order"attitude of conservatives than the maximum punishment judgment. While toughmindesness correlated with considering death penalty a category of punishment, it did not correlate significantly with maximum punishment. The latter seems to be determined by factors not assessed in the present study. Whereas there is even a greater heterogeneity in these scores they correlate lower with the personality variables than minimum punishment does.

While for conservatism and funniness of incongruity-resolution humor the size of the coefficient for maximum punishment is not much lower than the one for minimum punishment, this difference is larger for funniness of sexual humor, intolerance of ambiguity, and dogmatism. These variables have in common that they not only correlate with conservatism, but also with toughmindedness (Eysenck, 1954, Ruch \& Hehl, 1986). This again can be counted as evidence that it is the authoritarian personality (i.e., toughminded conservatives) (Adorno, Frenkel-Brunswik, Levinson \& Sanford, 1950) that is especially emphasizing the higher level of minimum punishment.

Finally, the results of the present study also give grounds to reconsider the value of humor. Humor generally is seen as a favorable trait and those not laughing at certain jokes are frequently accused as being humorless. Rating studies usually place "humor" highest in social desirability. The results of the present as well as of other studies demonstrate a more differentiated picture. There are aspects of humor that go along with, for example, a very punitive mind: Beware of humorous people.

\section{REFERENCES}

Adorno, T.W., Frenkel-Brunswik, E., Levinson, D.J. \& Sanford, R.N. (1950). The authoritarian personality. New York: Harper \& Row.

Allport, G.W. (1954). The nature of prejudice. London: Addison-Wesley.

Brengelmann, J.C. \& Brengelmann, L. (1960). Deutsche Validierung von Fragebogen dogmatischer und intoleranter Haltungen. Zeitschrift für experimentelle und angewandte Psychologie, 7, 451-471.

Cattell, R. B. \& Tollefson, D. L. (1966). The handbook for the IPAT humor test of personality. Champaign, IL: IPAT.

Cooper, C., Kline, P. \& May, J. (1986). The measurement of authoritarianism, psychoticism and other traits by objective tests: A cross-validation. Personality and Individual Differences, $\underline{7}, 15-21$.

Dixon, P.N., Willingham, W.K., Chandler, C.K. \& McDougal, K. (1986). Relating social interest and dogmatism to happiness and sense of humor. Individual Psychology Journal of Adlerian Theory, Research and Practice, $\underline{42}, 421-427$.

Eysenck, H.J. (1954). The psychology of politics. London. Routledge \& Kegan Paul.

Forabosco, G. \& Ruch, W. (1994). Sensation seeking, social attitudes, and humor appreciation in Italy. Personality and Individual Differences, 16, 515-528.

Kischkel, K.H. (1984). A scale to assess tolerance of ambiguity. Diagnostica, $\underline{30}$, 144-154 (in German).

Kline, P. \& Cooper, C. (1984). A construct validation of the Objective-Analytic Test Battery (OATB). Personality and Individual Differences, 5, 323-337.

McGhee, P.E., Ruch, W. \& Hehl, F.-J. (1990). A personality-based model of humor development during adulthood. Humor, $\underline{3}, 119-146$.

O'Connell, W. (1960). The adaptive functions of wit and humor. Journal of Abnormal and Social Psychology, $\underline{61}, 263-270$.

Rokeach, M. (1960). The open and closed mind: Investigations into the nature of belief systems and personality systems. New York: Basic Books. 
Ruch, W. (1983). Der Humor-Test 3WD (Form A, B und K). Unpublished manuscript. Department of Psychology, Düsseldorf, Germany.

Ruch, W. (1992). Assessment of humor: Studies with the 3-WD humor test. In Butcher, J. N. \& Spielberger, C. D. (Eds), Advances in personality assessment (Vol. 9, pp. 27-75), Hillsdale, NJ: Erlbaum.

Ruch, W., Accoce, J., Ott, C. \& Bariaud, F. (1991). Cross national comparison of humor categories: France and Germany. $\underline{\text { Humor, }} \underline{4,391-414 .}$

Ruch, W. \& Hehl, F.J. (1983). Intolerance of ambiguity as a factor in the appreciation of humour. Personality and Individual Differences, $\underline{4}, 443-449$.

Ruch, W. \& Hehl, F.-J. (1985). Diagnose des Humors - Humor als Diagnostikum. In F.J. Hehl, V. Ebel \& W. Ruch (Eds.), Diagnostik psychischer und psychophysiologischer Störungen, Vol. 2 (pp. 253-325). Bonn, Germany: Deutscher Psychologen Verlag.

Ruch, W. \& Hehl, F.J. (1986). Conservatism as a predictor of responses to humour-II. The location of sense of humour in a comprehensive attitude space. Personality and Individual Differences, $\underline{7}, 861-874$.

Ruch, W. \& Hehl, F.J. (1988). Attitudes to sex, sexual behaviour and enjoyment of humour. Personality and Individual Differences, $\underline{9}$, 983-994.

Schneider, J. \& Minkmar, H. (1972). Deutsche Neukonstruktion einer Konservativismusskala. Diagnostica, $\underline{18}$, 37-48.

Smith, D.R.J. and Levenson, H. (1976). Reactions to humor as a function of reference group and dogmatism. Journal of Social Psychology, 99, 57-61.

Wilson, G.D. (1973). A dynamic theory of conservatism. In G.D. Wilson (Ed.), The psychology of conservatism (pp. 257-266). London: Academic Press.

\section{AUTHOR NOTES}

The preparation of this manuscript was facilitated by a DFG-grant (Ru 480/5-1) awarded to Willibald Ruch. The manuscript was written during a research stay at the Department of Psychology, University of Delaware, Newark, DE. Correspondence and requests for reprints should be addressed to the first author at Department of Physiological Psychology, Heinrich-Heine-University of Düsseldorf, Universitätsstraße 1, 40225 Düsseldorf, Germany. 